\title{
TRANSLATION PROCEDURES IN PATIENT INFORMATION LEAFLETS
}

\author{
Rahmawati
}

Busmin Gurning

Sri Minda Murni

Diterima Mei 2018; Disetujui Juni 2018; Dipublikasikan Agustus 2018

\section{ABSTRACT}

The aims of this study were to find out the types of translation procedures in Patient Information Leaflets, to describe the realization of translation procedures and to explain about the reason of certain translation procedures realized in Patient Information Leaflets.The research was conducted by using qualitative descriptive design. The data of this study was translation unit that consists of words, phrases, clauses and sentences in Patient Information Leaflets in two versions, English as the source text and Bahasa Indonesia as the target text. The data was analyzed by using the theory of Translation Procedures based on (Vinay and Darbelnet ; 2000) to find the types, realization and the reason of certain translation procedures were used in Patient Information Leaflets. The results of the study were (1) there were eight types of translation procedures in patient information leflets namely borrowing, calque, literal translation, transposition, modulation, equivalent, deletion and mixing procedures. (2)There were some realization of translation procedures in patient information leaflets, namely pure loanwords, naturalization, word for word translation, optional transposition, obligatory transposition, free modulation, obligatory modulation, equivalency, reduction, and combining procedures, and (3) there were seven reasons behind the realization of translation procedures namely the concept of the source text is unknown, preserving the verbatim meaning of the source text, unequivalent grammatical structures between source language and target language, naturalism in translation, clarity in translation, familiarity and maintaining the original terms of the source text.

Key Words: Translation, Translation Procedures, Patient Information Leaflets, English and Bahasa Indonesia.

How to Cite: Rahmawati (2018).Translation Procedures in Patient Information Leaflets. Jurnal Linguistik Terapan Pascasarjana Unimed, 15 (2): 165-177 


\section{INTRODUCTION}

Translation is the best way to solve the problem of communicating in any kinds of languages in the world, but translation also demands people to master at least two or more language to conduct it. Besides, there are also some factors that should be considered by the translator to produce a good translation product that are linguistic and non linguistic factors. Linguistic factors consists of words, phrases and sentences while non linguistic factors cover the cultural knowledge on both source and target language culture (Nababan : 1999).

As a means of communication translation is therefore becomes an essential part in almost every field of life. In Indonesia nowadays we can find many products of translation either in education, culture and social field or economy like industries and manufactures.

Many manufactured products are marketed in countries other than the country of origin. However, non English speaking audiences will need to know about these products, and they need to understand the benefits and the how-to-use instructions of such products.

The instruction of manufacture products that is really important to understand before it is used by the users is PatientInformation leaflet. The present study focuses on Translation Procedure in Patient Information Leaflets (PIL).A Patient Information Leaflet (PIL) is a document enclosed in the sales package of a medicinal product and is written in the national language of the country where it is sold (Bongaarts: 2009 )

Indonesia as a developing country is also one of the consumer of pharmacy products from other countries and by the development of pharmacy industries many medicinal products are manufactured in Indonesia under license 1 other pharmacy companies all over the world. In order to make the patient information leaflet is easily understood by consumer in Indonesia the company provides in two versions, English version and the translation in Bahasa.

The existence of Patient Information Leaflet is very important for the patient because it provides useful information about the medicines that will be consumed by patients. It consists procedural information that instructs the reader what to do. These instructions do not only include the actions a user has to undertake, but also the conditions for an action and the consequences of an action ( Bongaarts : 2009).

Patient Information Leaflet as the instructive texts that its main function is instructing patients on how to use their medicine safely and correctly consists of much important information such as identification of medicine, indications for the product, information which patients need to be aware of prior to taking the medicine, dosage and usual instructions for use, description of side effects, how to store the product and other important information that the patients need. 
In this perspective, usability and readability of Patient Information Leaflet are also important, because the patient as the end user must have all correct information in order to use the medicine safely and effectively.

Nowadays, medicine can be bought over-the-counter or can be prescribed by a physician. In case the patient got it over-the-counter, without intervention of a physician so, the patient needs to decide for himself (whether it is with the help of the pharmaceutical assistant or not) which medicine is suitable. Nevertheless, many patients do not consult a pharmaceutical assistant (or buy medication at the chemistswhere the employees' knowledge of medication is in most cases either absent or very limited) and therefore gain no extra information about the medicine. For this reason, Patient Information Leaflets are very important especially for over-the-counter medication in order to enable the patient to weigh up the medicine's pros and cons and decide if the medicine is suitable in their situation.

In case of prescribed medication, the specific medicine has been advised by the physician and in an ideal situation the patient should be able to rely on the doctor's advice. However, physicians sometimes confine to give the complete information about the medicine's working and do not have any information (or ask about) a patient's medical history and use of other medication which could cause adverse reactions. Therefore, it is extremely important that a PIL provides information on these aspects.

Translating Patient Information Leaflet is not an easy work. It should be done carefully and accurately to prevent from deviating the actual intent. Inaccuracy in translating the Patient Information Leaflet can cause the fatal risk for the patients' health because it consists of all important information that the patient needs and to be aware of taking the medicine.

According to Buzarna (2015) translating medical text requires training extensive knowledge of the subject matter besides linguistic skills. This study tackels several translation procedures that covers Direct and Oblique Translation procedures and issues encountered in the translation of medical text that cover pragmatic, lingustic, cultural and text-specific which represents the starting point of the translation process. The result shows that in translating medical text the translator usually find some problems such as the differences in structure concerning syntax and vocabulary, both in source and target language, many abbreviations and acronyms that are commonly used in medical field and another major translating problem that is content error such as incorrect uses of terms, errors in writing and ambiguities. This study gives a picture and background references about Translation Procedures in translating medical text.

Other relevant study is conducted by Dewi (2011) aimed to analyze the translation procedure of the translation product in bilingual text. The selected data were analyzed based on theory of translation procedures by Vinay and Darbelnet (2000) to identify and classify the types of translation procedure used in the text in order to get description as far as the translation has the same term equivalent, accurate, acceptable and readable. The study conducted by Dewi is relevant to this current 
study since the findings can be used to support the analysis of translation procedures in this study, however there are several differences between the study conducted by Dewi and this current study. The difference lies in the data source. In the study conducted by Dewi the source of data is taken from bilingual text from BBC Indonesia News while the source of data in this current study is Patient Information Leaflet (PIL).

Patient Information Leaflet is considered as medical instructive text. According to Maes and Schellens in Bongaarts (2009) its purpose is to support the instructive function of the text and has function in defining, teaching, warning and advising something in the form of declarative information.

As it is categorized as medical text, Patient Information Leaflet is usually considered as scientific text and the product of its translation is regarded as scientific translation while according to Byrne in Pedersen and Halliday (2009) scientific translation deals with pure science in kind of theory whereas technical translation relates to the practical use of scientific knowledge. Scientific translation also has different purpose from technical translation. The previous has purpose to explain, justify, and convert the pure knowledge clearly while the latter has purpose to help someone do something or present new information to the audience or consumer. Scientific translation usually very formal while technical translation is more simple and not ambiguous. In line with that the translation of Patient Information Leaflet can be categorized as technical translation.

According to Byrne in Peddersen and Halliday (2009) The purpose of a technical translation isto present new technical information to a new audience, not to reproduce the source text or reflect its style or language. Every text has to be suited the reader in order for the reader to use the information easily, properly and effectively. This also means that the translator has to consider other things than just translating words for example the culture, in the respect that in one country a user guide is meant to instruct and in another to explain.It could be applied in Patient Information Leaflet since the reader is (in most cases) willing to take the medicine he has been prescribed, but he does not know how to use it safely and correctly.

In translating technical text, the translator usually face some problems such as there are many technical terms from source language that do not have equivalent meaning in target language. As the researcher found in the translation of Patient Information Leaflet. There are medical terms that have no equivalent meaning in the target language. So, it does not only need translator's knowledge about source and target language but also translator skill to preserve a proper equivalence of terms used in the field is needed in order to convey a good translation.

The phenomenonthat arise in translating patient information leaflets are the translator mostly took the medical terms directly from the source text with or without the adjustment of the spelling rules of the target language. Since the target reader of patient information leaflets are dominated by lay people that know little about medical terms, it causes the difficulty for the target reader to understand the product of translation or badly not understand the messages that will be conveyed. 
The quality of translation product depends on the translator. It means that if the translator does not do the translation process well, the quality of the translation product will decline. Therefore the translator is also responsible for the content of the translation product. That is why to achieve good translation products the translator should have adequate knowledge about translation procedures. The following is the example of phenomenon that the researcher found in the translation of patient information leaflets :

SL : The commonly observed adverse reactions are tachycardia and tremor TL : Efek samping yang sering dijumpai adalah takikardia dan tremor

In the sample above the word tachycardia in the source language was translated into takikardia in the target language. The translator took the word from the source language and used it in target language with some adjustment in the spelling rules of the TL. For the lay people as the target reader it would not be understood or probably cause misunderstanding of the meaning of the source language. According to Medical dictionary tachicardia means the high speed of the heart frequency that reach 100 per minute (for adult people). In this case, the translator applied borrowing procedure. To provide the clearer meaning or the accuracy in translation the translator can apply other types of translation procedures. The phenomenon above showed the importance of translation procedure in translation.

The writer in this thesis actually wants to see the product of translation that is in the form of translation of Patient Information Leaflets while English as the source text (ST) and Bahasa as the target text (TT). The writer wants to find out the procedures of translation used by translator. How they are realized and why the translator used those kinds of procedures.

According to Vinay and Dalbernet (2000) the procedure of translation can be divided into two main procedures, they are literal or direct translation; consists of Borrowing, Calque, and Literal translation, and oblique translation; consists of Transposition, Equivalent, Modulation and Adaptation. Literal or direct translation procedures are used when structural and conceptual elements of the source language can be transposed into the target language. For example, I love you very much which is translated into saya sangat mencintaimu, is the example of literal translation procedure because the direct transfer of source language text into a grammatically and idiomatically target text. Meanwhile, oblique translation procedures are used when the structural or conceptual elements of the source language cannot be directly translated without altering meaning or upsetting the grammatical and stylistics elements of the target language. For example, Hellowhich can be translated into halo, selamat pagi, etc,it is the example of modulation, because of the variation of the form of the message, obtained by a change in the point of view.

In this thesis, the writer would like to analyze the translation procedures found in the Patient Information Leaflets.

The following are the examples of translation procedure in Patient Information Leaflet :

\section{Example 1 :}




\section{TT : Terapi harus dihentikan saat ditemukan kontraindikasi}

In the sample above, the translator used direct translation procedure that is borrowing. According to Vinay and Darbelnet (2000) the translator used borrowing by incorporating a source text element into target text, by easily filling a gap in the target language and add a bit of source language colour to the target text. In this case, the translator directly carried over the lexical items from the source language ( English ) into target language ( Bahasa). The words therapy and contraindication are translated into terapi and kontraindikasi, in this case naturalized borrowing was realized by changing the form of the words without changing the meaning of the words. It was just changing or deleting some letters, like in translating as in the sample above the translator only deleted the letter $[\mathrm{h}]$ and changing the letter $[\mathrm{y}]$ become [i]. Actually the term theraphy can be translated into pengobatan but the translator left it untranslated. Therapy means the attempted remediation of a health problem, usually following the diagnosis. In the medical field, it is usually synoymous with treatment. In Indonesia the term terapi has been a common term and widely used. The translator left this term untranslated since indonesian has already known this term and would like to maintain the technical terms of the source language.

In case of translating the word contraindication the translator applied naturalized borrowing. It was only applied by changing the form of the word without changing the meaning. Actually the term contraindication has no equivalent term in Bahasa so the translator use the word kontraindikasi in the target language.

\section{Example 2:}

SL : Known, past or suspected breast cancer

TL : Diketahui mengidap, ada riwayat atau diduga adanya kanker payudara

It is clear that in the source text above, there was a source language that was translated into a target language by using Oblique translation Procedure namely transposition. For instance the word known is translated into diketahui mengidap. The translator changed the word into phrases.According to Vinay and Darbelnet (2000) Transposition is the procedure which involves replacing one word class with another without changing the meaning of the message. In this case, the translator translated the word known into phrase diketahui mengidap. The translator only changing the grammatical category without changing the meaning. It is done to get the stylistic effect in the translation.

The researcher is interested to analyze Translation Procedure in Patient Information Leaflet as first, it is the translation product which is issued by pharmaceutical company that has very important function to provide vital information about medicine for the patient especially the patient who consume the medicine for a long period. It is hoped that this research can be useful for many people. Second, the research about translation of medical or technical text is more needed nowadays as the development of technology and science so the researcher is interested to make a research in another source of data that is Patient Information Leaflet. Third, there are many problems in translation 
especially in translating scientific or technical text because there are many technical or scientific terms in the texts so the researcher would like to see what procedure that the translator used in translating Patient Information Leaflet (PIL).

\section{RESEARCH METHOD}

In conducting this research, the researcher used descriptive qualitative method. Qualitative research broadly defined means any kind of research that produces findings not arrived at by means of statistical procedures or other mean of quantification (Strauss and Corbin, 1998). According to Bogdan and Biklen (1992), qualitative is descriptive, where the data is in the form of words or pictures rather than numbers.

It is known as descriptive research. Donald stated that descriptive research methods are used to obtain information about existing condition and have widely used in educational research (Donald, 2009). Bogdan and Biklen assert that descriptive means the data collected are in the form of words rather than numbers. Qualitative methodologies refer to research procedures which produce descriptive data : people's own written or spoken words and behaviours. Descriptive qualitative design tries to analyze the data by translation. The research data was the embedded data research in the form of translation units in patient information leaflets with various procedures.

\section{FINDINGS AND DISCUSSIONS}

Having all the data been analyzed based on the three research problems, the findings are described as the following :

1. It was found that there were eight types of Translation Procedures used in translating patient information leaflets namely Borrowing (30,5\%), Calque (16.1\%), Literal Translation (3,8\%), Transposition (15,3\%), Modulation (11,4\%) and Equivalent (16.9\%), deletion (3,4\%), and mixing procedures $(2,5 \%)$. There was one procedure that was proposed by Vinay and Dalbernet that was not found namely : Adaptation, but the researcher found other new procedures namely deletion and mixing procedures. Deletion was applied by omitting the parts of source language and rendered into the shorter form in Target Language. There were some translation procedures proposed by Vinay and Dalbernet that could not be applied solely, so the translator combined two or more types of procedures. It can be said as Mixing Procedures.Asfigured out on the data display, there were twelve process how the translation procedures were realized in translating patient information leaflets namely : Pure loanwords $(10,6 \%)$, naturalization $(19,9 \%)$, structural calque $(9,7 \%)$, lexical calque $(6,8 \%)$, word for word translation $(3,8 \%)$, obligatory transposition $(4,2 \%)$, optional transposition $(11 \%)$, free modulation $(11 \%)$, obligatory modulation $(0.4 \%)$, equivalency $(16,9 \%)$, combining procedures $(2,5 \%)$ and reduction $(3,4 \%)$. 
2. From the analysis, the researcher found that in patient information leaflets, there were some reasons of using certain translation procedures, they were : maintaining original terms of the source language, naturality, clarity, familiarity, preserving the verbatim meaning of original language, unequivalent grammatical structure and the concept of the source text which is unknown in the target text.

3. It was found some reasons of the translator using certain translation procedures, they are : the concept of the source text is unknown, preserving the verbatim meaning, unequivalent grammatical structure, maintaining the original term of the source text, naturalism, clarity, and familiarity.

Dealing with the research findings above, there are some points as the important ones to be discussed in this study. It is very important to match whether the result of the study are contrastive to the theories.

The discussion of the types of translation procedures are forwarded, then the researcher investigates the findings of the types of translation procedures were used in Patient Information Leaflets and the theories. Furthermore, having investigated the findings, the researcher found there was a gap between the findings and the theories.

Vinay and Darbelnet (2000) divided translation procedures into two namely Direct or Literal Translation which cover three procedures and Oblique Translation cover four procedures namely borrowing, calque, literal translation, transposition, modulation, equivalent and adaptation, while according to research findings from seven translation procedures by Vinay and Darbelnet only six procedures were applied. They were : Borrowing, Calque, Literal Translation, Transposition, Modulation and Equivalent. But, the reseracher found another procedures that were not found in Vinay and Darbelnet's theory. They were considered as Deletion, and Mixing Procedures. There was one procedure of Vinay and Darbelnet's theory which was not found in this research namely adaptation.

Adaptation is used when the type of situation referred to by the SL message does not function or unknown in TL culture. In such cases the translator must recreate a situation that can be regarded as more or less equivalent (Walinski, 2015).

According to Jarniewicz in Walinski (2015), adaptation are particularly common in translation of books and movie titles. In translating Patient Information Leaflets, the translator did not use adaptation procedures may be because Patient Information Leaflets is a kind of medical text that can be categorized as scientific text which has characteristic as truth to particular reality, has referential meaning and rare to use idiomatic expression hence the translator did not find the SL message that cannot be found in TL culture. This findings is contrast with Muslim (2016) who investigated translation procedures of Pharasal verb in Breaking Down Novels. He found out that the 
procedure that was not applied in translating the novel is borrowing procedures since the data of his research was phrasal verbs while borrowing procedure is mostly used in words than phrases. Since the source of data of his analysis is novel which is considered as literary works which has expensive use of figurative language and idiomatic affixation so adaptation procedure should be applied by the translator.

According to the research findings there were also some data that were unable to translate by applying the seven Translation Procedures by Vinay and Darbelnet solely, hence, the researcher found some procedures to complete the translation process of Patient Information Leaflets. The procedure were deletion, note and mixing. Deletion was realized by reducting a part or some parts of the source language but without changing the meaning. It was applied to produce naturalism in translation. Note procedure was realized by adding additional information in the brackets or after the slash to provide the clearer meaning of the source language or prevent from misunderstanding of the maeanig of the SL. In this study note procedure was not applied solely but it was combined with other procedures. Combining two or more procedures was realized in this research since there were some data that were not be able to translate by using only one procedure, so the translator used other procedures. The finding of this study is in line with Lubis and Silalahi (2013) who analysed the translation procedures in Cultural terms. As the result of the study in translating cultural terms the translator applied note and deletion procedures and also mixing procedures that was called as couplet. This study also in line with Putri (2014) who investigated translation procedures in medical terms that also found that the translator also applied deletion procedure that was called reduction, mixing procedures that was considered as couplet procedures which was the combination of two or more translation procedures and note procedures which is the translator's way to give additional information to provide the clearest meaning for the reader. According to Newmark (1988) additional information in translation may take various forms, such as within the text, note at bottom of the page, notes at end of chapter, notes or glossary at end of book. In this study note procedure was applied by giving additional information of the terms in the bracket or after the slash. Based on the discussion of the types of translation procedure above it can be concluded that the types of translation procedures by Vinay and Darbelnet were not adequate in translating Patient Information Leaflets.

The mostly translation procedures used by translator in translating Patient Information Leaflets is borrowing procedure since there were many medical terms. It is very difficult to find out the proportional meaning of those terms in target language. So, to prevent from inaccuracy of translating the terms the translator prefer to borrow or took the word directly from the source language into target language. According to Silalahi (2009) the purpose of the translator of medical text mostly used borrowing procedure to translate medical terms is to create the universality and familiarity hence the terms that were used in one country can be understood by the user in other places. It contrast to the investigation did by Dewi (2010) who found that in translating the bilingual 
text in BBC Indonesian News the mostly translation procedures is Literal translation and Transpositon. These translator procedures are used to keep the meaning in the TL approximately as equal as in the SL text.

According to Vinay and Darbelnet (2000) Borrowing procedures is most frequently used since new technologies entering rapidly the surrounding reality. Another reason for using borrowing is that the concept discussed in the source text is relatively unknown to the target audience. As pointed out by Vinay and Darbelnet, perhaps the most interesting aspect of using borrowings relates to creating specific stylistic effects in order to introduce the flavour of the source language (SL) culture into a translation, the translators may use the foreign terms. In such cases the translator does not want to leave the foreign element of the source text. Usually, the terms borrowed from English is associated with the modern socio-economic development. As patient Information Leaflets consist of many medical terms the translator tend to use the same format as the source language.

Based on the research findings there were twelve process of the realization of translation procedures in patient information leaflets. They were pure loanwords, naturalization, structural calque, lexical calque, word for word translation, optional transposition, obligatory transpostion, free modulation, obligatory modulation, equivalency, reducting and combining two or more procedures. Based on the theory Vinay and Darbelnet there were only ten process of realizing the translation procedures in patient information leaflets namely pure loanwords, naturalization, structural calque, lexical calque, word for word translation, optional transposition, obligatory transposition, free modulation, obligatory modulation and equivalency while reduction and combining two or more procedures were not found.

According to Lubis and Silalahi (2013) in translation, the longer construction of the term in source language can be rendered into the shorter one in the target language or when is needed it can be omitted to give the clearer meaning into target language that was called as reduction. While the realization of combining two or more procedures that was not found in Vinay and Darbelnet's theory was considered as couplet process in Newmark (1988) that was realized by rendering a source language terms into target language by means of two or more translation procedures at once.

In this study there were seven reasons of using certain translation procedures in translating Patient Information Leaflets. The first is the Concept of the source text is unknown. Since the translator would like to find the equivalent or the closest equivalent procedure if the concept of the source text is unknown in the target text. It is impossible to translate it literally.

The second reason is preserving the verbatim meaning of original text. In this case literal translation was applied since the application of this procedure can keep the original message of the source language to prevent the misleading in translation. Then the third reason is unequivalent grammatical structure. It was possible since English as the source language has different grammatical structure with bahasa as the target text. Providing the naturalism in translation was also becoming the 
reason of the translator in using certain translation procedure. This reason was mostly found when the translation used modulation procedure where there was a change of point of view between the source text and the target text. The last three were clarity, maintaining original terms in the source language and familiarity.

The most dominant reason of using certain translation procedure was maintaining original term of the source language. Since there were many medical terms in patient information leaflets so the translator decided to use the terms of the source language and used it in the target language.

Based on the discussions above it can be concluded that this study is contrary to the theory proposed by Vinay and Darbelnet (2000).

\section{CONCLUSIONS}

From overall analysis of Translation Procedures in Patient Information Leaflets, it was concluded that :

1. Based on the data analysis that has been found in the research of Translation Procedure, there were eight translation procedures used in translating patient information leaflets namely Borrowing, Calque, Literal Translation, Transposition, Modulation, Equivalent, Deletion and mixing procedures.

2. There were twelve realization of translation procedures in patient information leaflets, namely : pure loanwords, naturalization, lexical calque, structural calque, word for word translation, obligatory transposition, optional transposition,. Free modulation, obligatory modulation, equivalency, combining and reduction. The most dominant realization was naturalization since the translator took the words or expression form source language and used it in the target language with some adjustment as the spelling rules of the target language.

3. There were seven reasons of using certain translation procedures, they were : The concept of the source text is unknown, Preserving verbatim meaning of original text, Unequivalent grammatical structure, Maintaining the original terms of the source language, naturalism in translation, clarity and familiarity.

\section{REFERENCES}

Ahmadi,S and Ketabi,S. 2011.Translation Procedures and Problems of Color Idiomatic Expressions in English and Persian: Cultural Comparison in Focus. Journal ofUniversity of Isfahan, Volume 4. No. 17, December 2011. Accessed on 22 February 2016.

Bogdan,C.R \& Biklen, S.K., 1992. Qualitative Research for Education: An Introduction Theory and Method, 2nd edition. Needham Heights, M.A: Allyn and Bacon. 
Bongaarts, L. 2009. Translating Patient Information Leaflets. MA Thesis: Utrecth University Press.

Bell,T. R. 1991. Translation and Translating: Theory and Practice. 1st Ed. New York: Longman

Bryman, A. 2000. Triangulation. Leicertershire : Loughborough University Press.

Buzarna, A. 2015. Procedures and Difficulties in the Translation of Medical Texts. An English Romanian Case Study. ISBN 978-606-8624-21-1 Journal of Language and Discourse, volume. 1, No. 1, February 2015. Tugu Mures Publication. Accessed on 22 February 2016.

Catford, J.C. 1965. A Linguistic Theory of Translation. London: Oxford University Press.

Chen, Y. 2014. The Consistency Degree in the Use of Translation Procedurs: A Pilot Study. The International Journal for Translating \& Interpreting Reseach. Volume 1. No.13, December 2014. Wenzao Ursuline University of Language. Accesed from trans-int.org on 2 March 2016.

Dewi, N. 2014. Translation Procedures of Bilingual Texts in BBC Indonesia News. Journal of volume 2, No. 2. Accessed from http://ojs.unud.ac.id on 15 October 2015.

Denzin, N. K. and Lincoln, Y. S. 1994. Introduction : Entering the Field of Qualitative Research. Thousands Oaks, CA : Sage.

Fedora, L. 2015. An analysis of Procedures in Translating Cultural Words and Their Meaning Shift Found in the Indonesian Novel Laskar pelangi.Journal of Vivid. Volume 4. No.1. English Departement, Andalas University. Accessed on 22 February 2016.

Gibova, K. 2012. Translation Procedures in the Non Literary and Literary Text Compared. ISBN 978-80-555-0503-9. Volume 2, No. 5. Journal of language and Translation, University Kniznica Pressovkej. Accessed on 22 December 2015.

Gil, A.B. 2011. Procedures, Techniques, Strategies: Translation Process Operators. Journal of volume 17, No. 3. Accessed from http://www.informaworld.com on 15 October 2015.

Guerra, A. 2012. Translating Culture: Problems, Stragies and Practial Realities. ISSN 1847-7755. Journal of Literature, Culture and Literary Translation, Volume 12, No. 1. Accessed from doi: 10.15291/sic/1.3.1t.1 on 22 December 2015.

Hadithya, O. 2014. Translation Procedures Used in Translating Computer Terms from English into Bahasa Indonesia. Journal of Vivid. Volume 3. No.2. English Departement, Andalas University. Accessed on 22 December 2015.

Hatim, B and Jeremy, M. 2004.Translation: An Advance Resource Book. London: Routledge.

Herman. 2015. A Direct Translation Analysis of Mobile Phone User Guides: An Applied Linguistics Study.Journal of Humanites and Social Science. Journal of volume 20, No 3. Accessed From www.iosrjournals.org on January 2016.

Ordudari, M. 2007. Translation Procedure. Strategies, and Method. Journal of volume 2, No 2. Accessed from http://translationjournal.net/journal/41 culture.htm on 20 February 2016.

Larson, L.M. 1984. Meaning Based Translation. 2nd Ed. New York: University Press of America.

Machali, R. 2000. Pedoman Bagi Penerjemah, Jakarta: Grasindo.

Mashhady, H., Pourgalavi, M., and Fatollahi, M. 2015. Newmark's Procedures in Persian Translation of Golding's Lord of the Flies. Journal of volume 3, No. 1. Accessed from http://www.eltsjournal.org on 27 January 2016. 
Munday,J. 2001. Introducing Translation Studies: Theories and Application. London : Routledge.

Nababan, M.R. 1999. Teori Menerjemah Bahasa Inggris. Yogyakarta: Pustaka Pelajar.

Neubert, A. 1985. Text and Translation. Leipzig: Verlag.

Newmark, P. 1988. Textbook of Translation, 1st Ed. U.K: Prentice Hall.

Ni, L. 2009. English Language Teaching (For Translation Theories). Journal of Volume 2, No. 2. Accessed from www.ccsenet.org/journal.html on 15 December 2015.

Nida, E and Taber, C. 1969. The Theory and Practice of Translation. Leiden: E.J. Brill.

Pedersen, A.T. and Halliday, T.N. 2009. Translating Medical Article. Copenhagen Business School.

Pinchuck, I. 1977. Scientific and Technical Translation. London: Andre-Deutsch.

Rossum, J. 2015. A Comparison of Translation Procedures between Amateur and Professional Subtitlers. Thesis. Leiden University.

Shakenia, S. 2011. A Comparative Study of the Persian Subtitles of American Historical Drama and Romantic Comedy Movies with the Original. ISSN 1799-2591. Theory and Practice in Language Studies, Volume 1. No.6, pp. 740-743, June 2011 (c) 2011 Academy Publisher Manufactured in Finland. Accessed from doi: 10.4304/tpls.1.6.740-743 on 15 December 2015.

Silalahi, M. and Lubis, S. 2013. Translation Procedures of Cultural Terms Found in Sejarah Bilingual for The Students of Senior High School. ISSN 1693 - 4660. Kajian Linguistik 2013, 275 291. Program Studi Linguistik SP-s USF. Accessed on 10 February 2016.

Siregar, R. 2009. Analisis Penerjemahan dan Pemaknaan Istilah Teknis : Studi Kasus Pada Terjemahan Dokumen Kontrak. Thesis. Universitas Sumatera Utara.

Vaxjo, K. 2013. Translating Medicine from English to Swedish: A Translation Study of a Text About Diabetes.Thesis.LinneUniversitetet. Accessed on 15 December 2015.

Venuti, L., 2000. The Translation Studies Reader. London: Routledge

Vinay, J. P. and Darbelnet. 1995. Stylistiquecomparée du francaiset de l'anglais: Méthode de Traduction. Paris: Didier. Translated and edited by J.C. Sager and M.J. Hamel. 1995 as Comparative Stylistics of French and English: A Methodology for Translation. Amsterdam and Philadelphia, PA: John Benjamins.

Vinay, J.P. and Darbelnet, J. 2000. A Methodology for Translation In: Venuti, L, editor. The Translation Studies Reader. NewYork: Routledge.

Widyamartaya,A. 1989. Seni Menerjemahkan. Yogyakarta: Kanisius

Zainurrahman.2009. The Theories of Translation: From History to Procedures. Translation Directory. 